\title{
Cerebellar tract alterations in PLS and ALS
}

Sicong $\mathrm{Tu}^{1,2,3}$, Ricarda A.L. Menke ${ }^{2,3}$, Kevin Talbot ${ }^{3}$, Matthew C. Kiernan ${ }^{1}$, Martin R. Turner ${ }^{2,3}$

${ }^{1}$ Brain and Mind Centre, Sydney Medical School, University of Sydney, Sydney, Australia.

${ }^{2}$ Wellcome Centre for Integrative Neuroimaging, University of Oxford, UK.

${ }^{3}$ Nuffield Department of Clinical Neurosciences, University of Oxford, UK.

\section{Correspondence:}

Dr. Sicong Tu

Wellcome Centre for Integrative Neuroimaging

John Radcliffe Hospital

OX3 9DU

UK

sicong.tu@nden.ox.ac.uk
Prof. Martin Turner

West Wing Level 6

John Radcliffe Hospital

OX3 9DU

UK

martin.turner@ndcn.ox.ac.uk

Word count: 814

References: 13 


\begin{abstract}
The cerebellum shows neuropathological change in a number of neurodegenerative conditions where clinical involvement is not the primary feature, including amyotrophic lateral sclerosis (ALS). Whether these changes are associated with disruption to the direct cerebellar tract pathways to the motor cortex and spinal cord in ALS is uncertain. Diffusion tensor imaging was used to examine the integrity of two primary cerebellar pathways, the dentato-rubro-thalamocortical (DRTC) and spino-cerebellar (SC) tracts. ALS patients with an upper motor neuronpredominant phenotype $(n=9)$, were matched to a group with the upper motor neuron-only condition primary lateral sclerosis (PLS, $n=10)$ and healthy controls $(n=17)$. Significant alterations across diffusion metrics in the DRTC proximal to the motor cortex were found in both patient groups. PLS patients were found to have an independent diffusion abnormality in the cerebellar region of the DRTC and SC tracts. Disruption to primary cerebellar tracts in PLS is therefore postulated, adding to other markers of its divergent pathogenesis from ALS.
\end{abstract}

Keywords: amyotrophic lateral sclerosis, primary lateral sclerosis, diffusion tensor imaging, cerebellum 


\section{Short Report}

MRI has identified progressive cerebellar degeneration in ALS, although typically without overt

clinical signs ${ }^{23}$, perhaps masked by a high burden of corticospinal tract pathology. However, in the rarer upper motor neuron (UMN) only condition of primary lateral sclerosis (PLS), disrupted cerebro-cerebellar connectivity has been specifically identified ${ }^{4}$.

To investigate the integrity of direct cerebellar pathways to the motor cortex and spinal cord, the dentato-rubro-thalamo-cortical (DRTC) and spino-cerebellar (SC) tracts were examined in a group of PLS and UMN-predominant sporadic ALS patients, alongside healthy controls. UMN burden was used as selection criteria so that differences in observed neural alterations would not simply reflect greater clinical UMN involvement inherent to PLS. A previously validated pathological reflex scale of UMN burden was employed ${ }^{5}$.

Patients were recruited from the 'BioMOx' cohort (PLS = 10, ALS =9, healthy controls $=17$ ). All ALS patients fulfilled categories of 'probable' or 'definite' according to revised El Escorial criteria. Groups were matched for: age (mean 60, SD 10.7), years of education (mean 14.9, SD 4), clinical UMN burden [0-15; ALS, mean 13.4 (SD 1.1); PLS, mean 14 (SD 1.6)], and revised ALS functional rating scale score [ALSFRS-R; ALS, mean 33.9 (SD 6.5); PLS, mean 33 (SD 5.7). ALS and PLS groups significantly differed in disease duration [ALS, mean years 2.7 (SD 1.9); PLS, mean years 12.2 (SD 8.5)] and disability progression rate [ALS, mean 0.5 (SD 0.2); PLS, mean 0.1 (SD 0.1)]. Whole-brain diffusion images (3T; 60 directions; b-value $=1000$ $\mathrm{s} / \mathrm{mm}^{2} ; 2 \mathrm{~mm}^{3}$ voxel; 65 slices) were acquired. Scans were preprocessed using FSL and tractography carried out using PROBTRACKX ${ }^{6}$. The DRTC was reconstructed using masks of the dentate nucleus, and contralateral red nucleus, thalamus, and motor cortex. The SC was 
reconstructed using masks placed in the inferior cerebellar peduncle at the upper medulla level of the brain, and in the ipsilateral cerebellar hemisphere at the same axial slice. The DRTC tract was thresholded at 30\% and divided into 4 segments based on anatomical landmarks to account for inherent regional variations in diffusivity across the brain. Group differences across diffusion metrics were calculated using ANOVA, followed by planned comparisons of each dependent variable between cohorts using Bonferroni correction.

Diffusivity alterations were detected in the thalamic and motor cortical segments of the DRTC in both patient groups compared with controls (Fig. 1). PLS patients showed independent diffusion abnormality in the caudal cerebellar region of the DRTC and SC (Fig. 2).

----INSERT FIGURE 1----

----INSERT FIGURE 2----

In ALS, structural changes have been detected in the dentate gyrus and cerebellar hemispheres, primarily affecting regions integrated in sensorimotor and executive control brain networks ${ }^{13}$, becoming more prominent with disease progression ${ }^{7}$. The changes seen here in the thalamic segments of the DRTC are in keeping with the detection of thalamic pathology mirroring cortical involvement ${ }^{8}$. Volumetric changes in the cerebellum have not been prominent in PLS studies to date, in contrast to the 'knife-edge' pre-central gyrus frequently observed ${ }^{9}$. White matter abnormalities have however been reported in the middle cerebellar peduncle alongside increased cortical connectivity, primarily with the motor cortices ${ }^{4}$.

These findings suggest that disruption in afferent and efferent cerebellar pathways is more extensive in PLS than previously recognized, which may have additional value alongside emerging functional connectivity markers of the ALS-divergent pathogenesis of PLS ${ }^{10}$. The 
dissociation in white matter integrity along the DRTC and SC in the brain stem region may also reflect more widespread diffusivity alteration as a result of longer disease duration. Clinical cerebellar signs are not a prominent feature of PLS, but a broader spinocerebellar network dysfunction may contribute to the symptom of dysequilibrium in particular. One feature that may be further investigated in relation to cerebellar dysfunction is saccadic abnormality, which is causally regulated by firing of neurons in the dentate nucleus ${ }^{11}$. Latency and error rate in saccades during visual search paradigms were significantly elevated in a subset of the current PLS cohort ${ }^{12}$.

The conclusions that can be confidently drawn here are limited by low sample size. The selective comparison using ALS patients with high UMN burden means that the observed dissociation in cerebellar pathways alterations may not be applicable to the broader syndrome of ALS.

Nonetheless, white matter degradation in this sub-group of ALS may be most prominent proximal to the motor cortex along tracts connected to the brainstem in contrast to those with PLS, and supports further investigation of the cerebellum's role in the wider ALS-FTD spectrum 13. 


\section{Acknowledgements}

The authors thank all the study participants for their efforts and enthusiasm for clinical research. The Oxford MND Centre (MRT, KT) receives funding from the Motor Neurone Disease Association. ST is funded by the Australian National Health and Medical Research Council CJ Martin Early Career Fellowship (APP1121859). MCK was supported by the Australian National Health and Medical Research Council Program Grant (Forefront \#1037746). MRT is funded by the Medical Research Council and Motor Neurone Disease Association Lady Edith Wolfson Senior Clinical Fellowship (MR/K01014X/1).

\section{Financial Disclosure:}

The authors report no financial disclosures. 


\section{Authorship}

\begin{tabular}{|c|c|c|c|}
\hline Name & Location & Role & Contribution \\
\hline $\begin{array}{l}\text { Sicong Tu, BSc, } \\
\text { MSc, } \mathrm{PhD}\end{array}$ & $\begin{array}{l}\text { University of Oxford, } \\
\text { Oxford, UK }\end{array}$ & Author & $\begin{array}{l}\text { Design and } \\
\text { conceptualized study; } \\
\text { analyzed the data; } \\
\text { drafted the } \\
\text { manuscript for } \\
\text { intellectual content }\end{array}$ \\
\hline $\begin{array}{l}\text { Ricarda A.L. Menke, } \\
\text { BSc, PhD }\end{array}$ & $\begin{array}{l}\text { University of Oxford, } \\
\text { Oxford, UK }\end{array}$ & Author & $\begin{array}{l}\text { Major role in the } \\
\text { acquisition of data; } \\
\text { interpreted the data; } \\
\text { revised the } \\
\text { manuscript for } \\
\text { intellectual content }\end{array}$ \\
\hline $\begin{array}{l}\text { Kevin Talbot, } \\
\text { MBBS, PhD, FRCP }\end{array}$ & $\begin{array}{l}\text { University of Oxford, } \\
\text { Oxford, UK }\end{array}$ & Author & $\begin{array}{l}\text { Major role in the } \\
\text { acquisition of data; } \\
\text { interpreted the data; } \\
\text { revised the } \\
\text { manuscript for } \\
\text { intellectual content }\end{array}$ \\
\hline $\begin{array}{l}\text { Matthew C. Kiernan, } \\
\text { MBBS, PhD, DSc, } \\
\text { FRACP }\end{array}$ & $\begin{array}{l}\text { University of Sydney, } \\
\text { Sydney, Australia }\end{array}$ & Author & $\begin{array}{l}\text { Interpreted the data; } \\
\text { revised the } \\
\text { manuscript for } \\
\text { intellectual content }\end{array}$ \\
\hline $\begin{array}{l}\text { Martin R. Turner, } \\
\text { MBBS, PhD, FRCP }\end{array}$ & $\begin{array}{l}\text { University of Oxford, } \\
\text { Oxford, UK }\end{array}$ & Author & $\begin{array}{l}\text { Major role in the } \\
\text { acquisition of data; } \\
\text { interpreted the data; } \\
\text { revised the } \\
\text { manuscript for } \\
\text { intellectual content }\end{array}$ \\
\hline
\end{tabular}




\section{References}

1. Gellersen HM, Guo CC, O'Callaghan C, et al. Cerebellar atrophy in neurodegeneration-a meta-analysis. J Neurol Neurosurg Psychiatry 2017 doi: 10.1136/jnnp-2017-315607

2. Prell T, Grosskreutz J. The involvement of the cerebellum in amyotrophic lateral sclerosis. Amyotroph Lateral Scler Frontotemporal Degener 2013;14(7-8):507-15. doi: 10.3109/21678421.2013.812661

3. Bede $P$, Elamin $M$, Byrne $S$, et al. Patterns of cerebral and cerebellar white matter degeneration in ALS. J Neurol Neurosurg Psychiatry 2015;86(4):468-70. doi: 10.1136/jnnp-2014-308172

4. Meoded A, Morrissette AE, Katipally R, et al. Cerebro-cerebellar connectivity is increased in primary lateral sclerosis. Neuroimage Clin 2015;7:288-96. doi: 10.1016/j.nicl.2014.12.009

5. Turner MR, Cagnin A, Turkheimer FE, et al. Evidence of widespread cerebral microglial activation in amyotrophic lateral sclerosis: an [11C](R)-PK11195 positron emission tomography study. Neurobiol Dis 2004;15(3):601-9. doi: 10.1016/j.nbd.2003.12.012

6. Keser Z, Hasan KM, Mwangi BI, et al. Diffusion tensor imaging of the human cerebellar pathways and their interplay with cerebral macrostructure. Front Neuroanat 2015;9:41. doi: 10.3389/fnana.2015.00041

7. Bede $P$, Hardiman O. Longitudinal structural changes in ALS: a three time-point imaging study of white and gray matter degeneration. Amyotroph Lat Scl Fr 2018;19(3-4):232-41. doi: 10.1080/21678421.2017.1407795

8. Tu S, Menke RAL, Talbot K, et al. Regional thalamic MRI as a marker of widespread cortical pathology and progressive frontotemporal involvement in amyotrophic lateral sclerosis. J Neurol Neurosurg Psychiatry 2018 doi: 10.1136/jnnp-2018-318625

9. Pringle CE, Hudson AJ, Munoz DG, et al. Primary lateral sclerosis. Clinical features, neuropathology and diagnostic criteria. Brain 1992;115 ( Pt 2):495-520.

10. Clark MG, Smallwood Shoukry R, Huang CJ, et al. Loss of functional connectivity is an early imaging marker in primary lateral sclerosis. Amyotroph Lat Scl Fr 2018:1-8. doi: 10.1080/21678421.2018.1517180

11. Kunimatsu J, Suzuki TW, Tanaka M. Implications of Lateral Cerebellum in Proactive Control of Saccades. J Neurosci 2016;36(26):7066-74. doi: 10.1523/JNEUROSCI.0733-16.2016

12. Proudfoot M, Menke RA, Sharma R, et al. Eye-tracking in amyotrophic lateral sclerosis: A longitudinal study of saccadic and cognitive tasks. Amyotroph Lateral Scler Frontotemporal Degener 2015;17(1-2):101-11. doi: 10.3109/21678421.2015.1054292

13. Tan RH, Devenney E, Dobson-Stone C, et al. Cerebellar integrity in the amyotrophic lateral sclerosisfrontotemporal dementia continuum. PLoS One 2014;9(8):e105632. doi:

10.1371/journal.pone.0105632 


\section{Figure Legend}

Figure 1. Group average representation of the left (blue) and right (red) dentato-rubro-thalamocortical (DRTC) tract. The DRTC is split into 4 segments: 1) dentate nucleus - pre-decussation, 2) post-decussation - pre-thalamus, 3) thalamus, 4) post-thalamus - motor cortex. Diffusivity value of the DRTC is shown along each segment in ALS, PLS and control participant cohorts. Significance at $\mathrm{p}<0.05: *$ PLS vs control; **ALS vs control; *** PLS vs ALS; $\boldsymbol{a}$ PLS vs ALS/Control; $\boldsymbol{b}$ ALS vs PLS/control; $\boldsymbol{c}$ control vs ALS/PLS.

Figure 2. Group average representation of the left (blue) and right (red) spino-cerebellar (SC) tract. Diffusivity value of the SC is shown along each axial slice in ALS, PLS and control participant cohorts. Significance at $\mathrm{p}<0.05: \boldsymbol{a}$ PLS vs ALS/Control. 